\title{
Effect of biochar and ameliorant on maize (Zea mays L.) growth in a field experiment
}

\author{
Yuanxin Fu ${ }^{\mathrm{a}}$, Qian Zhang ${ }^{\mathrm{b}}$, Guocheng Liu ${ }^{\mathrm{c},}$ * \\ College of Environmental Science and Engineering, Ocean University of China, Qingdao 266100, \\ China \\ a fuyx627@163.com, b start2633264901@163.com, ciceliugc@126.com
}

Keywords: light sierozem, biochar, maize, ameliorant

\begin{abstract}
Lack of water resource and nutrient deficiency retard crop production in the light sierozem in Ningxia, China. Biochar and biochar-based ameliorant present a feasible solution to solve these problems. This study investigated the effect of adding biochar or biochar-based ameliorant on the growth of maize (Zea mays L.) in the light sierozem. The application of biochar and biochar-based ameliorant increased the dry biomass of maize by $13.6 \%$ and $11.4 \%$, respectively. Moreover, the biochar-based ameliorant addition effectively improved the grain number per row by $8.1 \%$ and grain yield by $9.2 \%$. These results indicated that the application of the biochar and the biochar-based ameliorant could be promising amendments for improving the light sierozem.
\end{abstract}

\section{Introduction}

Soil, as an important natural resource, is the material basis of human survival and services for the balance of many small but vital terrestrial ecosystems. However, soil resource has been becoming infertile and degradation, even facing depletion and nutrients leaching. In China, approximate 135 million hectare of arable soil must support 1.3 billion population at least, increasing at the rate of 5.2\%o [1]. Soil quality and productivity are highly related to food security, agronomic modernization, and social sustainable development [2]. However, increasing food production in the limited cultivated land to meet the needs of growing population is a new and inevitable challenge [3]. Light sierozem, widely distributed among the arid desert areas in the northwest of China, especially in Ningxia, is lack of water resource and subjected to nutrient deficiency. It is an urgent and underlying task to ameliorate the light sierozem and stimulate its regeneration to maintain sustainable development of agriculture.

The amelioration techniques of light sierozem generally depend on irrigation, fertilization, and development of drought-resistant plants. However, these methods possibly result in secondary salinization and desertification [4]. Recently, biochar from charring biomass at above $250{ }^{\circ} \mathrm{C}$ in the absence of oxygen has gradually attracted increasing interests, which puts forward a feasible and economical solution for remediating the degraded soils $[5,6]$. Biochar products had been widely considered as efficient soil conditioners in improving soil fertility and increasing plant growth and crop productivity [7]. Also, numerous researches demonstrated that biochar addition into soil could improve soil structure, reduce nutrient leaching, and thus enhance plant growth [8]. However, most studies were restricted to the laboratory experiments, thus the effect of biochar on crop growth and yield in field is still unclear yet. This study aimed to investigate the effects of adding biochar and biochar-based ameliorant on field crop growing in the light sierozem in Ningxia, China.

\section{Materials and methods}

The field experiment was conducted in experimental base in Ningxia Academy of Agricultural and Forestry Sciences. The soil is typical light sierozem, of which properties have been reported in our previous study [9]. Maize (Zea mays L.), a dominant crop in Ningxia, was chosen as the tested plant.

Biochar was pyrolyzed from peanut shell at $350{ }^{\circ} \mathrm{C}$ for $2 \mathrm{~h}$ under the condition of $\mathrm{N}_{2}$, and then was ground for further application. Meanwhile, a biochar-based ameliorant (BCA) was prepared by blending the peanut shell-derived biochar, peanut shell powder, and ammonium nitrate followed by 
stabilization for 30 days. Considering the cost and the effect of peanut shell biochar in previous research [9], the rate of $1.5 \%(\mathrm{w} / \mathrm{w})$ was chosen in this field experiment, equal to 3.15 ton per hectare.

Urea fertilizer was applied to the soil as base fertilizer. The field experiment was subjected to three treatments: no amendment $(0 \%), 1.5 \%(\mathrm{w} / \mathrm{w})$ biochar, and $1.5 \%(\mathrm{w} / \mathrm{w})$ biochar-based ameliorant, hereafter referred to as $\mathrm{CK}, \mathrm{BC}$, and $\mathrm{BCA}$, respectively. Each treatment was setup with three duplicates. After BC and BCA application, the soil was rototilled to $10 \mathrm{~cm}$ depth. Maize were grown on the filed plots with plant density of 5500 per acre.

After 5 months, the ear and plant height of the maize were determined. Then, the ears of maize were air-dried in room and the ear rows and grain number per row were measured. Shoot and root biomass were separated followed by deactivation of enzymes at $105{ }^{\circ} \mathrm{C}$ for $30 \mathrm{~min}$ and drying to constant weight at $60^{\circ} \mathrm{C}$. The dry biomass of shoot and root and grain yield were weighed. All data were analyzed as means and standard deviation. The least significant difference (LSD) method was adopted to perform post hoc comparison using Statistical Product and Service Solutions (SPSS 20.0)

\section{Results and discussion}

As shown in Fig. 1a, BC and BCA addition to soil significantly increased the maize height compared with that of CK. However, BC and BCA application had no significant effect on the ear height (Fig. $1 \mathrm{~b})$. The results indicated that biochar indeed has potential to improve the maize growth in field. Although no significant difference in the dry biomass was observed between different treatments, BC and BCA adding increased the dry biomass of maize by $13.6 \%$ and $11.4 \%$ (Fig. 2a), respectively. The possible mechanism for this positive response is that the biochar alters the soil structure, increases water-holding capacity, and then stimulates root elongation. Similarly, the grain yield of 15 maize was greatly increased by $9.2 \%$ in the BCA treatment and by $3.9 \%$ in the $\mathrm{BC}$ treatment compared with that in CK, respectively (Fig. 2b).

Ear rows and grain number per row are vital parameters for determining the maize output. The BC and BCA addition did not increase the ear rows, but the number of grain per row was increased by $8.1 \%$ especially in the BCA treatment (Fig. 3). The augment of the number of grain per row may be explained by that BCA provided more nutrients (e.g., $\mathrm{N}$ and organic matter) for maize growth and improved the urea utilization efficiency [10].
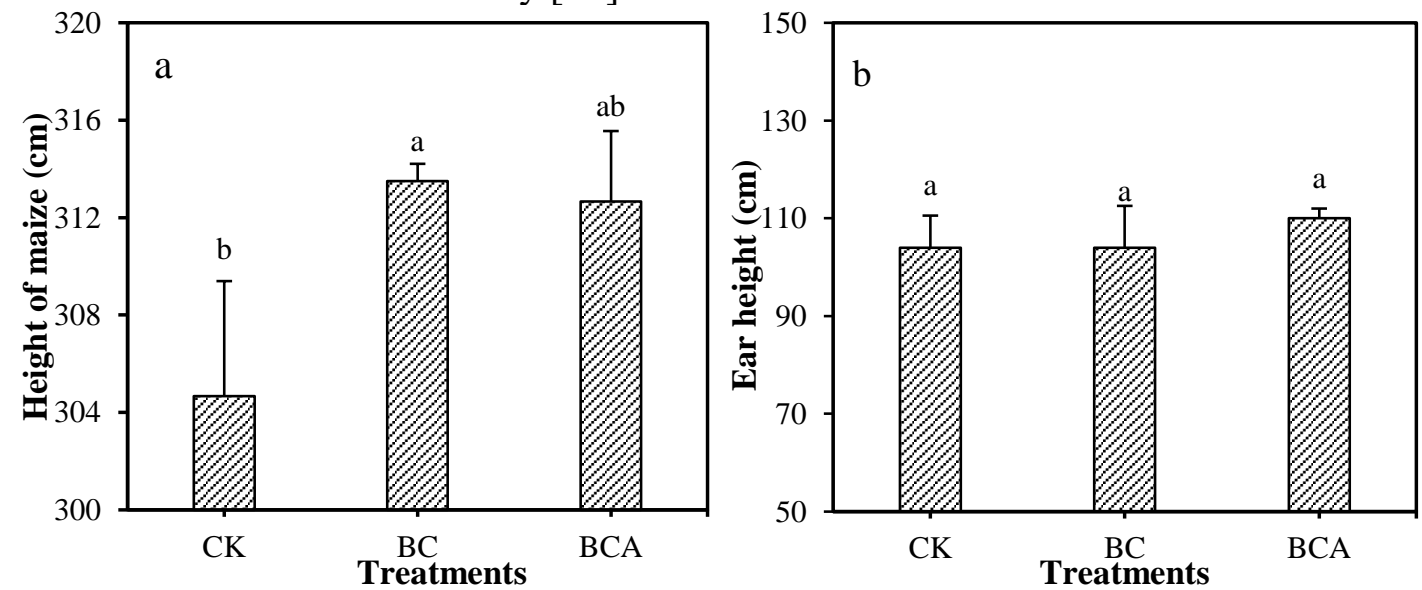

Fig. 1 The effect of BC and BCA addition on maize height (a) and ear height (b). The different lowercase letters represent significant difference between the treatments $(P<0.05)$ 

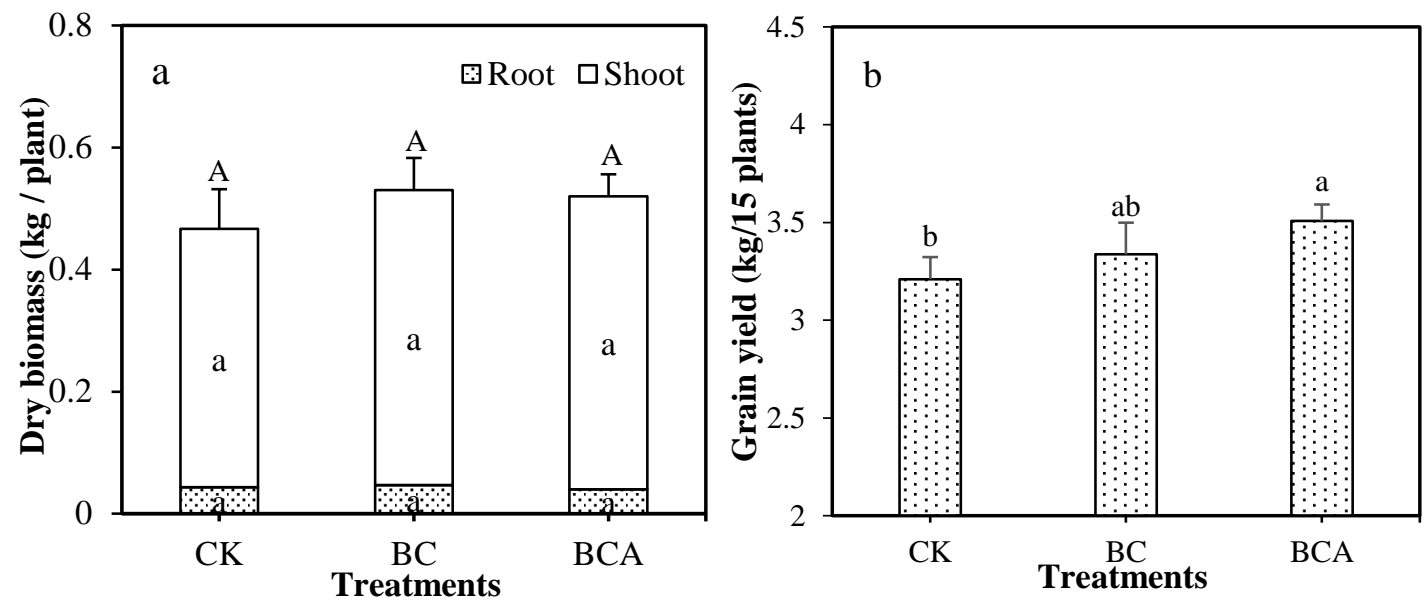

Fig. 2 The effect of BC and BCA addition on dry biomass (a) and grain yield of 15 plants (b). The different lowercase letters represent significant difference of shoot and root biomass between the treatments $(P<0.05)$ and the uppercase letters indicate significant difference of total biomass between the treatments $(P<0.05)$.
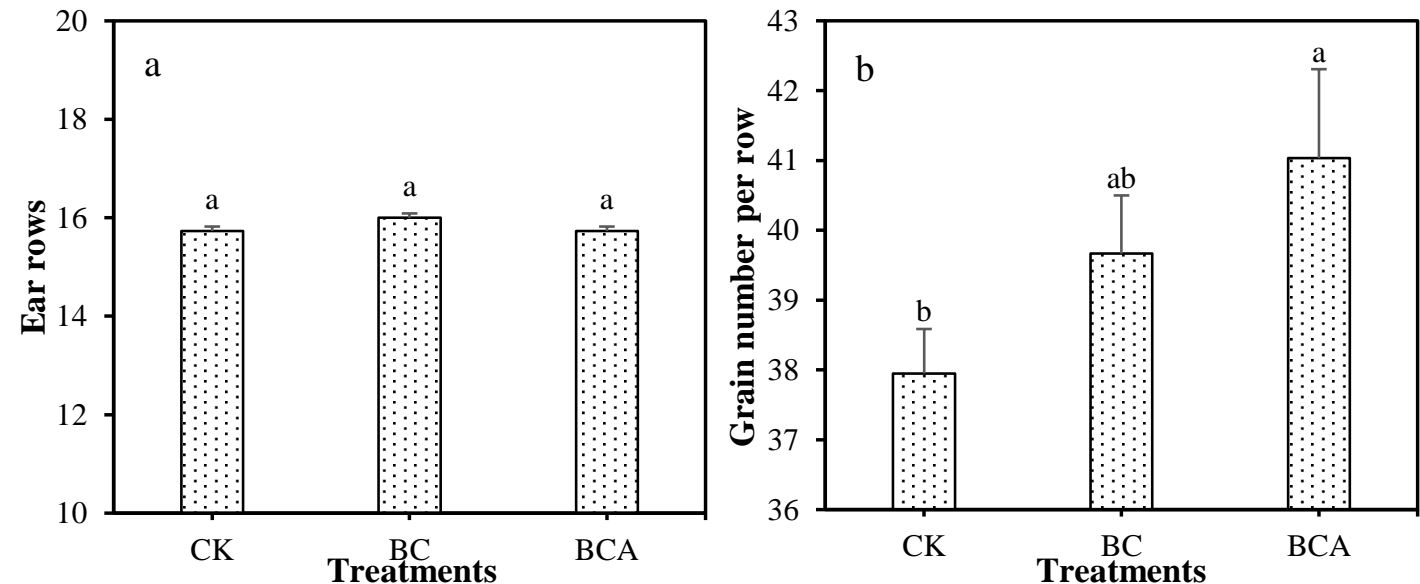

Fig. 3 The effect of BC and BCA addition on ear rows (a) and grain number per row (b). The different lowercase letters represent significant difference between the treatments $(P<0.05)$.

\section{Conclusions}

The results of field experiment confirmed that $\mathrm{BC}$ and $\mathrm{BCA}$ had positive effects on maize growth in light sierozem. The application of BC and BCA markedly stimulated the plant height of maize, but did not increase the ear height. After BC and BCA were added into the light sierozem, the grain yield of maize was also increased significantly. Further, adding BCA could increase the grain number per row and had potential to promote the crops output in the tested light sierozem. Overall, the application of $\mathrm{BC}$ and $\mathrm{BCA}$ exhibited great promise in light sierozem amendment.

\section{Acknowledgements}

This study was supported by National Natural Science Foundation of China (41325013).

\section{References}

[1] Zhang F, Chen X, Vitousek P. Chinese agriculture: An experiment for the world: Nature Vol. 497 (2013), p. 33-35

[2] Teng $\mathrm{Y}, \mathrm{Wu} \mathrm{J}, \mathrm{Lu} \mathrm{S}$, et al. Soil and soil environmental quality monitoring in China: a review: Environment international Vol. 69 (2014), p. 177-199

[3] Tilman D, Cassman K G, Matson P A, et al. Agricultural sustainability and intensive production practices: Nature Vol. 418 (2002), p. 671-677 
[4] Jin G, Ma Y. Development and utilization of light sierozem in Ningxia: Arid zone research Vol. 17(2000), p. 59-63

[5] Ippolito J A, Laird D A, Busscher W J. Environmental benefits of biochar: Journal of environmental quality Vol. 41 (2012), p. 967-972

[6] Barrow C J. Biochar: potential for countering land degradation and for improving agriculture: Applied Geography Vol.34 (2012), p. 21-28

[7] Zheng H, Wang Z, Deng X et al. Characteristics and nutrient values of biochars produced from giant reed at different temperatures: Bioresource Technology Vol. 130 (2013), p. 463-471

[8] Lehmann J, Rillig M C, Thies J, et al. Biochar effects on soil biota-a review: Soil Biology and Biochemistry Vol. 43 (2011), p. 1812-1836

[9] Wang Z, Song X, Chen L et al. The effect of addition biochar on rape growth and nitrogen utilization in light sierozem of Ningxia: Periodical of Ocean University of China Vol. 45 (2015), p. $94-101$

[10] Zhang D, Pan G, Wu G, et al. Biochar helps enhance maize productivity and reduce greenhouse gas emissions under balanced fertilization in a rainfed low fertility inceptisol: Chemosphere Vol. 142 (2016), p. 106-113 